\title{
Geographical variations in infant and child mortality in West Africa: a geo-additive discrete-time survival modelling
}

\author{
Ezra Gayawan ${ }^{*}$, Mumini I. Adarabioyo ${ }^{3}$, Dorcas M. Okewole², Stephen G. Fashoto ${ }^{4}$ and Joel C. Ukaegbu ${ }^{2}$
}

\author{
* Correspondence: \\ egayawan@futa.edu.ng; \\ gayawane@run.edu.ng \\ 'Department of Statistics, Federal \\ University of Technology, Akure, \\ PMB 704 Akure, Ondo State, Nigeria \\ Full list of author information is \\ available at the end of the article
}

\begin{abstract}
This study examines the residual geographical variations in infant and child mortality and how the different categories of the risk factors account for the spatial inequality in West African countries. To this end, we pooled data for 10 of the countries extracted from Demographic and Health Surveys and used the spatial extension of discrete-time survival model to examine how the variables exert influence on infant and child mortality across space. Inference was Bayesian based on the computational efficient MCMC technique. We found different geographical patterns for infant and child mortality. In the case of children under five, demographic factors inherent to the mother and child as well as maternal status variables when accounted for explain away a good part of the huge variations observed in the crude rates. There are no evidence of significant variations, however, in infant mortality except for three neighbouring regions of Liberia and Sierra Leone. The findings can guide in evidence-based allocation of scarce resources in West Africa with the aim of improving the survival chance of young children.
\end{abstract}

Keywords: Child mortality, Spatial analysis, West Africa, Environmental factors, Mother's status, MCMC

\section{Introduction}

Sub-Saharan Africa has continued to bear the enormous burden of infant and child mortality with an under-five mortality rate of 92 deaths per 1000 live births, more than 15 times the average for developed regions (UN Inter-Agency Group for Child Mortality Estimation 2014). Child mortality experienced in West Africa is more than double the rate for most countries in the northern or southern Africa (Balk et al. 2004; MDG Report 2012), also see Table 1. Among the West African countries, the experience is disproportionate (Table 1). Even within countries, it is well documented that aggregate levels of morbidity and mortality conceal spatial variations. Given that causes of childhood morbidity and hence mortality are multifaceted and operate in many complex ways, suitable methodologies that address these complexities are required to examine them. When applied, the methods would allow for the understanding of hidden patterns, including spatial variations which are central in designing effective community-based intervention programmes.

(c) 2016 The Author(s). Open Access This article is distributed under the terms of the Creative Commons Attribution 4.0 International License (http://creativecommons.org/licenses/by/4.0/), which permits unrestricted use, distribution, and reproduction in any medium, provided you give appropriate credit to the original author(s) and the source, provide a link to the Creative Commons license, and indicate if changes were made. 
Table 1 Infant and child mortality rates for the countries under study and for selected North and Southern African countries. Included for the countries under study are the numbers of children under age 5 years and those below age 1 and year of the DHS

\begin{tabular}{|c|c|c|c|c|c|}
\hline \multirow[t]{2}{*}{ Country } & \multirow{2}{*}{$\begin{array}{l}\text { Under-five } \\
\text { mortality rate }^{a}\end{array}$} & \multirow{2}{*}{$\begin{array}{l}\text { Infant mortality } \\
\text { rate }^{a}\end{array}$} & \multirow{2}{*}{$\begin{array}{l}\text { Year of } \\
\text { survey }\end{array}$} & \multicolumn{2}{|c|}{ Sample size for the study } \\
\hline & & & & Children under age 5 & Infant (under age 1) \\
\hline Benin & 70 & 42 & $2011-2012$ & 13,407 & 3168 \\
\hline Burkina Faso & 129 & 65 & 2010 & 15,044 & 3825 \\
\hline Cote d'Ivoire & 108 & 68 & $2011-2012$ & 7776 & 2130 \\
\hline Ghana & 80 & 50 & 2008 & 2992 & 804 \\
\hline Guinea & 123 & 67 & 2012 & 7039 & 1877 \\
\hline Liberia & 94 & 54 & 2013 & 7606 & 1988 \\
\hline Mali & 95 & 56 & 2012-2013 & 10,326 & 2608 \\
\hline Niger & 127 & 51 & 2012 & 12,558 & 3119 \\
\hline Nigeria & 128 & 69 & 2013 & 31,482 & 8262 \\
\hline Sierra Leone & 156 & 92 & 2013 & 11,938 & 3315 \\
\hline Egypt & 27 & 22 & 2014 & & \\
\hline Morocco & 47 & 40 & 2003-2004 & & \\
\hline Namibia & 54 & 39 & 2013 & & \\
\hline Total & & & & 120,168 & 31,096 \\
\hline
\end{tabular}

${ }^{a}$ Culled from reports of the DHS. Rates are based on 5 years prior to the dates of surveys

Much attention has been given to the causes of child mortality in the developing world, and several individual, socioeconomic, demographic and environmental factors have been examined. The understanding is that improvement in healthcare services alone might not result in the well-being of children as most illnesses are discreetly influenced by lifestyle (Babalola and Fatusi 2009; Foggin et al. 2001), socioeconomic and environmental factors (Foggin et al. 2001; Folasade 2000), cultural attributes (Gesler 1992; Kandala et al. 2006) and level of utilization of healthcare services (Atari and Mkandawire 2014; Gayawan 2014b). Studies by Kazembe and Namangale (2007), Kandala et al. (2006), Kandala et al. (2007) and Gayawan et al. (2014) identified the risk factors of childhood morbidity especially fever, cough, diarrhoea and pneumonia to include age, use of bed nets for sleeping, type of household roofing materials, feeding practices and, notably, the geographical location of a child. These studies reaffirmed the views of Kalipeni (1993) that the district in which a child is born sets the context for risk factors of child morbidity and mortality.

Policymakers are often interested in knowing the distribution of health outcomes according to geographical regions or the association with environmental and socioeconomic factors and how these factors exert influence at different locations. In this regard, mapping the spatial variations in child mortality becomes a critical tool. The need for adopting a geographical approach in analysing child mortality is vital as it would assist in identifying specific areas with high or low risks, thereby assisting in health planning and allocation of scarce resources. The majority of previous studies on infant and child mortality have largely depended on classical correlation and regression analyses. Statistical outcomes produced by these procedures are aggregates and can be misleading if generalized for all local areas. Some authors have examined spatial inequality in childhood morbidity and mortality in West African countries. Analysing data from Nigeria, Adebayo and Fahrmeir (2005) and Adebayo et al. (2004) found 
significant variations in infant and child mortality based on geographical settings. Gayawan and Turra (2015) mapped the geographical variations in risk factors of child mortality in Nigeria. On their part, Balk et al. (2004) found that in West Africa, spatial variables explained a good deal of the country-specific variations in mortality and that they are associated with household characteristics. However, there is the need to look beyond specific country and scrutinize detailed geographical variations among the West African countries in a manner that transcends frontiers. This would broaden our knowledge of the variability and assist in the allocation of scarce resources.

This article reports the analyses involving data from 10 West African countries with the aim of elucidating geographical differences in infant and child mortality among regions of the countries. We particularly concentrate on whether there are significant regional variations in infant and child mortality among the countries and if there are, what category of variables can explain such variations. The study adopts Bayesian and geo-statistical techniques to the data from Demographic and Health Surveys to unravel the geographical inequality. We rely on spatial extension of the discrete-time survival model (Fahrmeir and Tutz 2001). Discreet-time model allows for analysing time as a discreet phenomenon and is therefore considered appropriate in this case because survival times of children are given in months only. The predictors include non-parametric effects of time scale and continuous covariates, spatial components and a linear part in additive form.

In order to fully understand how the risk factors exert influence on mortality among the children and across space in West Africa, we categorize the variables into three: demographic variables that are inherent to the mother and child, variables that are related to mother's status and those related to amenities available to households where the child belongs. Contextual factors, which measured unobserved or unmeasured risk factors, are introduced as random effects. It was anticipated that infant deaths might be more related to endogenous factors such as low birth weight and hereditary diseases (Balk et al. 2004; Kembo and Van Ginneken 2009) while mortality among older children would come from preventable diseases and malnutrition, which are often caused by socioeconomic and culture-related factors (Cleland and van Ginneken 1988; Kembo and Van Ginneken 2009). Therefore, we first run the analyses for all children under five and then repeated the same for infants, those below age 1 year.

\section{Conceptual issues of child mortality}

There have been extensive studies on the impact of socioeconomic, environmental and demographic factors on child survival in the developing world. We provide a brief review that would guide the choice of variables to be included in this study. The study by Caldwell (1979) in an urban city of Nigeria was one of the foremost detailed researches to outline the nexus between education and child survival. Following this submission, studies in several other countries have reaffirmed the direct link between parental education and child mortality (Adetunji 1995; Cleland and van Ginneken 1988; Defo 1996; Folasade 2000; Hobcraft 1993; Iyun 1992). Women who attain higher level of education are more likely to marry later, play significant roles on issues pertaining to themselves and their children, be well informed on the best approach to manage illnesses, attend the required number of antenatal care and give birth at available health facilities 
(Babalola and Fatusi 2009; Gayawan 2014a; Iyun 1992). Their children are therefore likely to be well nurtured and enjoy better health.

The pace of childbearing, parity and maternal age have similarly been listed among important factors that shape the survival chance of children in developing countries (Hossain and Islam 2008; Kembo and Van Ginneken 2009; Manda 1999; Mturi and Curtis 1995). Specifically, women who have too many births and those with births that often occur too close together have unpleasant experience of child survival. Rapid succession of births may erode the mother of the required reproductive and nutritional resources since her nutritional reserve would not have fully recovered, leading to higher prevalence of premature and feeble births (Pebley and Stupp 1987). Theory suggests that young mothers have reproductive systems that are not entirely mature and therefore suffer from severe complications during delivery, resulting in high morbidity for themselves and their children. Also, these women do not adequately utilize maternal healthcare services (Gayawan 2014a; Magadi et al. 2007). Older women, by reason of ageing, have declining maternal resources, and thus, children born to these women compete for the limited resources and this inhibits their survival chances (Balk et al. 2004; Manda 1999; Miller et al. 1992). Consequently, maternal age at birth and birth order exhibit a U-shape relationship with childhood mortality (Kandala and Gebrenegus 2006; Sastry 1997).

Environmental factors including access to safe water, sanitation, hygiene and indoor smoke from solid fuel cannot be glossed over when discussing grounds of childhood morbidity and mortality. Unsanitary refuse and excreta disposal and use of unsafe drinking water increase the risks of diarrhoeal diseases, cholera and typhoid which are among the leading causes of childhood deaths (Macassa et al. 2004; Yassin 2000). Lack of awareness of the health consequences of these unhygienic manners and infrequent hand washing compound the risks for children. Further, deficient drainage system and accumulated waste water found in many sprawling settlements located in the majority of the urban cities in sub-Saharan Africa encourage the breed of mosquitoes with the increased risk of malaria, which is a significant cause of death among young children (MDG Report 2012). Children strapped to the back of their mothers during cooking are exposed to indoor air pollution from the use of biomass fuel, and the result is enhanced risks of acute respiratory infection (ARI) (Janjua et al. 2012).

Cultural practices and gender preference equally shape child survival in most developing countries. Some African societies consider exclusive breastfeeding as dangerous to infants while handful feel colostrum is too dirty to be given to newborns. Water and other local foods are therefore introduced early in life while herbal teas are given as a first line for treating illnesses (Davies-Adetugbo 1997; Osayande 1998). Gender preference causes discriminatory practices against children of less-desired sex. Because of the seeming bride price to be earned, female children are often most favoured and better nourished than their male counterparts, resulting in skewed social and health consequences for children (Fuse 2010; Klasen 1996). Mother's working status and household income level have also been examined and found to affect child survival in the developing world (Adebayo and Fahrmeir 2005; Kalipeni 1993) 


\section{Material and method \\ Data}

The study relies on data set from Demographic and Health Surveys (DHS) conducted in the 10 West African countries under study. The DHS programme has, over the years, provided technical assistance to surveys in several developing countries, thereby advancing global understanding of health and population trends. DHS has developed standard procedures, methodologies and manuals to guide the survey processes and to ensure that the data properly reflect the situations they are intended to describe and are comparable across countries and over time. The sampling frames used for the surveys were based on the population and housing censuses conducted by the various agencies and commissions vested with such responsibilities by the constitutions of the countries. The primary sampling units were defined on the basis of the enumeration areas (EAs) from the Census frames. DHS samples are usually selected using two-stage stratified design. The numbers of clusters were first selected from the list of EAs followed by the selection of households at the second stage. All women aged 15-49 years present at the selected households are eligible to participate in the survey.

The study utilized data from surveys conducted between 2008 and 2013. Since the data were collected within a relatively short period of time, period effect on mortality is minimal (Balk et al. 2004). West African countries included in the study and the year of survey are as follows: Benin (2011-2012), Burkina Faso (2010), Cote d'Ivoire (2011-2012) Ghana (2008), Guinea (2012), Liberia (2013), Mali (2012-2013), Niger (2012), Nigeria (2013) and Sierra Leone (2013). As of the time of this study, data available for Togo were from the 1998 survey and are considered to be relatively old to be included. Figure 1a shows a portion of the map of Africa with countries under study shaded, while the regions of each country are shown in Fig. 1b. In the case of Mali, three regions, namely Tombouctou, Gao and Kidal, were not covered during the surveys and were therefore excluded. The sample size analysed for each country is presented in Table 1. Data refer to children born in the 5 years prior to the surveys. Demographic variables that were considered inherent to the mother and child are maternal age, type of place of residence, child's birth order, whether or not birth was single, sex of the child and sex of the household head. Variables classified as mother's status include mother's educational attainment, household wealth index and mother's working status. Amenity variables include electricity, toilet facility, water source, place of delivery and exposure to media (newspaper, radio and television; whether or not the mother was exposed to each of these at least once a week). The regions, being the spatial unit of analysis, were geo-referenced. In all, 84 regions were included in the analyses. Table 2 presents the categorization for each of the variables and the frequency distribution of the children included.

\section{Statistical methods}

In discrete-time survival analysis, the discreet timescale is partitioned into $k$ intervals $\left\{I_{t}=\left[a_{t-1}, a_{t}\right)\right\}$ with $0=a_{0}<a_{1}<\ldots<a_{k}<\infty$. It is assumed that all censoring happen at the end of the intervals and the intervals need not necessarily be of equal length. Let 


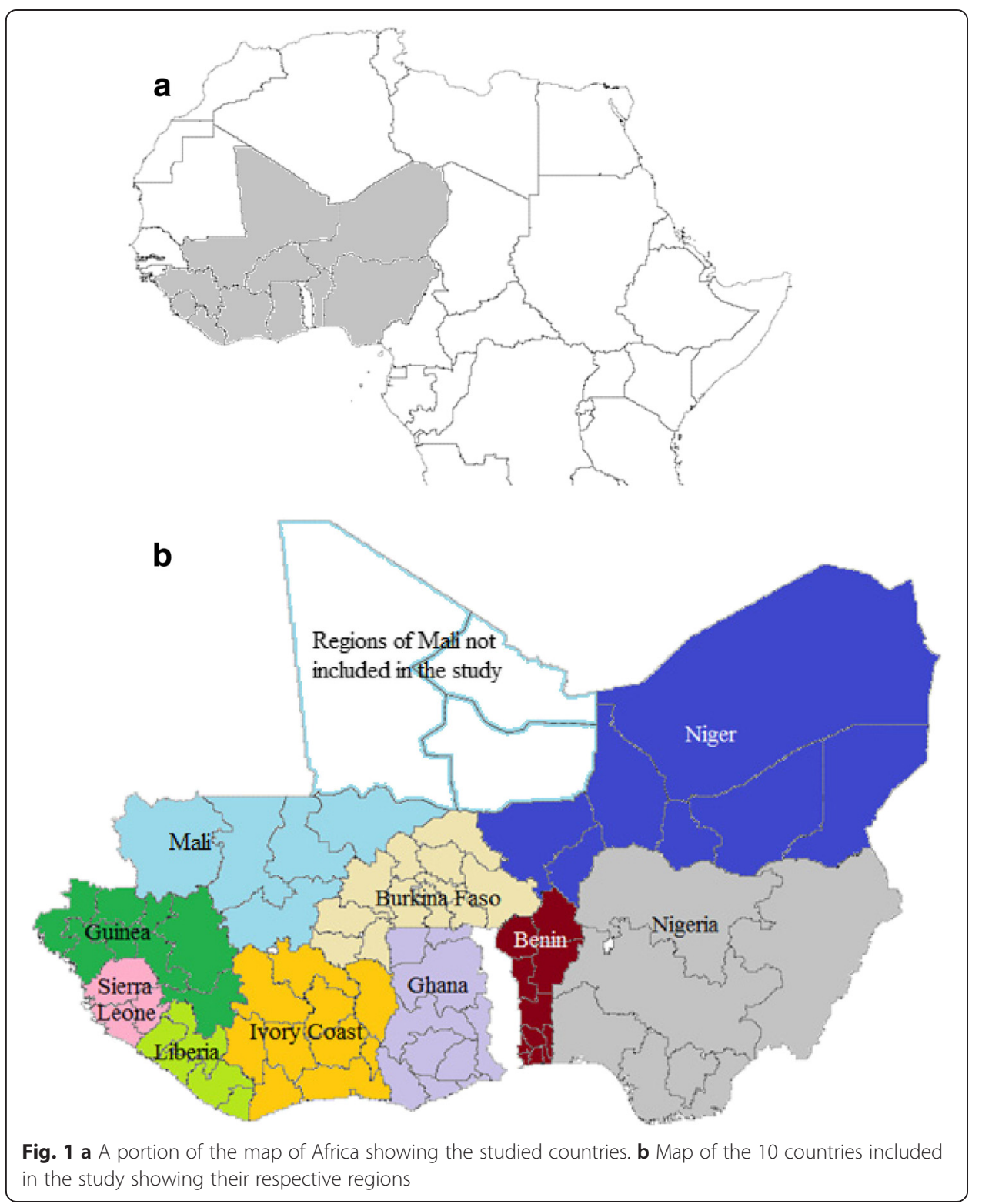

the discrete time $T=t, t \in\{1,2, \ldots, k\}$ denote the observed event in months after birth in the interval $I_{t}$. Assume further that $x_{i t}=\left(x_{1 t}, \ldots, x_{r t}\right)$ denote a vector of covariates. Then, the discrete hazard function, which is the conditional probability of failure (death) occurring in interval $\left[a_{t-1}, a_{t}\right)$ given that the child survives to the beginning of the interval, is given by

$$
\lambda\left(t \mid x_{i t}\right)=P\left(T=t \mid T \geq t, x_{i t}\right) .
$$

The corresponding discrete survival function, which is the probability of surviving beyond $a_{t}$, is given by

$$
S\left(t \mid x_{i t}\right)=P\left(T>t \mid x_{i t}\right)=\prod_{t=1}^{t}\left(1-\lambda\left(t \mid x_{i t}^{\mathrm{it}}\right)\right)
$$

Survival information on each child is recorded by $\left(t_{i}, \delta_{i}\right), i \in\{1, \ldots, N\}$, where $t_{i} \in\{1$, $\ldots, 60\}$ is the child's observed survival time in months and $\delta_{i}$ is the survival indicator 
Table 2 Categorization of variables and the frequency distribution of the children under age 5

\begin{tabular}{|c|c|c|}
\hline Variables & Sample size & Percentage \\
\hline \multicolumn{3}{|l|}{ Place of residence } \\
\hline Urban & 35,497 & 29.5 \\
\hline Rural & 84,671 & 70.5 \\
\hline \multicolumn{3}{|l|}{ Birth order } \\
\hline 1st birth & 23,498 & 19.6 \\
\hline 2nd or 3rd order & 39,928 & 33.2 \\
\hline 4th or higher order & 56,742 & 47.2 \\
\hline \multicolumn{3}{|l|}{ Multiple birth } \\
\hline Yes & 4703 & 3.9 \\
\hline No & 115,465 & 96.1 \\
\hline \multicolumn{3}{|l|}{ Sex } \\
\hline Female & 59,022 & 49.1 \\
\hline Male & 61,146 & 50.9 \\
\hline \multicolumn{3}{|c|}{ Sex of the household head } \\
\hline Male & 104,052 & 86.6 \\
\hline Female & 16,116 & 13.4 \\
\hline \multicolumn{3}{|l|}{ Educational attainment } \\
\hline No education & 79,688 & 66.3 \\
\hline Primary & 20,343 & 16.9 \\
\hline Secondary or higher & 20,111 & 16.7 \\
\hline \multicolumn{3}{|l|}{ Wealth } \\
\hline Poorest & 27,422 & 22.8 \\
\hline Poorer & 26,036 & 21.7 \\
\hline Middle & 24,583 & 20.4 \\
\hline Richer & 22,914 & 19.1 \\
\hline Richest & 19,213 & 16.0 \\
\hline \multicolumn{3}{|l|}{ Working status } \\
\hline No & 42,566 & 35.4 \\
\hline Yes & 77,330 & 64.4 \\
\hline Missing & 272 & 0.2 \\
\hline \multicolumn{3}{|l|}{ Has electricity } \\
\hline No & 87,512 & 72.8 \\
\hline Yes & 32,552 & 27.1 \\
\hline Missing & 104 & 0.1 \\
\hline \multicolumn{3}{|l|}{ Toilet facility } \\
\hline Non-improved & 75,404 & 62.7 \\
\hline Improved & 44,680 & 37.2 \\
\hline Missing & 84 & 0.1 \\
\hline \multicolumn{3}{|l|}{ Water source } \\
\hline Others & 2359 & 2.0 \\
\hline Surface & 18,698 & 15.6 \\
\hline Well & 72,338 & 60.2 \\
\hline Pipe & 25,599 & 21.2 \\
\hline Missing & 1174 & 1.0 \\
\hline
\end{tabular}


Table 2 Categorization of variables and the frequency distribution of the children under age 5 (Continued)

\begin{tabular}{lll}
\hline Place of delivery & & \\
Any other place & 56,672 & 47.1 \\
Hospital & 62,793 & 52.3 \\
Missing & 703 & 0.6 \\
Exposure to mass media & & \\
Newspaper & & 91.7 \\
No & 110,149 & 8.0 \\
Yes & 9671 & 0.3 \\
Missing & 348 & \\
Radio & & 38.7 \\
No & 46,469 & 61.2 \\
Yes & 73,484 & 0.2 \\
Missing & 215 & 64.5 \\
Television & & 35.3 \\
No & 77,501 & 0.3 \\
Yes & 42,363 & 13.4 \\
Missing & 304 & 4.7 \\
Type of cooking fuel & & 80.8 \\
Any other & 16,061 & \\
Electricity/gas & 2074 & \\
Kerosene & 4915 & \\
Wood & 97,075 & \\
\hline
\end{tabular}

with $\delta_{i}=1$ if child $i$ is dead and $\delta_{i}=0$ if the child is still alive. Therefore, for $\delta_{i}=1, t_{i}$ is the age at death; otherwise, it is the age at the time of the survey.

The event of death of the $i$ th child could be considered as a sequence of binary outcomes and can therefore be cast into the framework of binary regression models (Fahrmeir and Tutz 2001) by defining a binary event indicator $y_{i t}$ with

$$
y_{i t}= \begin{cases}1 & \text { if } t=t_{i} \text { and } \delta_{i}=1 \\ 0 & \text { if } t<t_{i}\end{cases}
$$

The indicator $y_{i t}$ could be linked to the covariates $x_{i t}$ by an appropriate link function for binary response model such as probit, logit or complementary log-log function and a predictor $\eta_{i t}\left(x_{i t}\right)$ as a function of (discrete) time $t$ and the covariates. The hazard function (1) for the $i$ th child can then be written as a binary response model

$$
P\left(y_{i t} \mid x_{i t}\right)=h\left(\eta_{i t}\right)
$$

where $h$ is an appropriate response or link function. In this case study, we assumed the logit link. This can then be linked to the covariates; thus,

$$
\eta_{i t}=\gamma_{0 t}+x_{i t} \xi
$$

where $\gamma_{0 t}$ corresponds to the baseline effect and $\xi$ is a vector fixed effects parameter. In an entirely parametric framework, the baseline is frequently modelled by a few dummy variables, dividing the time axis into a number of segments, or by some low-order 
polynomial. However, non-parametric modelling offers a more flexible framework to explore unknown patterns of the baseline as it is expected that the hazard would change smoothly between time points.

Because of the spatial structure of the data at hand and the possible non-linear effects of some covariates, predictor (5) is generalized to a geo-additive predictor

$$
\eta_{i t}=\gamma_{0 t}+f\left(x_{i t}\right)+f_{\text {spat }}\left(s_{i}\right)+v_{i t}^{\prime} \xi
$$

where $f\left(x_{i t}\right)$ is a smooth function for the non-linear effects of continuous covariates, e.g. mother's age, $f_{\text {spat }}\left(s_{i}\right)$ is the non-linear spatial effect of the region of residence and the vector $v_{i t}^{\prime}$ comprises of categorical covariates with $\xi$ as a vector of the parameters. The spatial effect may further be split up into spatially correlated (structured) and uncorrelated (unstructured) effects since spatial structure is a substitute of many unobserved influencing factors, some of which may have strong spatial structure while others may only be present locally.

To estimate model parameters and smooth functions, a fully Bayesian approach was adopted and priors assigned as appropriate. In modelling the spatially structured effects, an intrinsic conditional autoregressive (CAR) prior, which introduces a neighbouring structure to the regions, was assumed (Besag et al. 1991). The prior assumes that the mean for each area $\phi_{i}$, conditional on the neighbouring areas, has a normal distribution with mean equal to the average of the neighbouring areas $\phi_{l}$ and variance inversely proportional to the number of neighbours $m_{i}$. Under contiguity, with $w_{i j}=1$ if areas $i$ and $l$ are adjacent and $w_{i j}=0$ otherwise, the CAR prior has the form:

$$
\phi_{i} \mid\left\{\phi_{l} ; \sim i\right\}^{\sim} N\left(\frac{i}{m_{i}} \sum_{\widetilde{l}_{i}} \phi_{l}, \frac{\sigma_{\phi}^{2}}{m_{i}}\right)
$$

where $l \sim i$ denotes sites $i$ and $j$ are adjacent areas and $\sigma_{\phi}^{2}$ is a spatial variance that controls for the degree of smoothness. The unstructured heterogeneity was modelled using exchangeable normal prior $\theta_{i}^{\sim} N\left(0, \sigma_{\theta}^{2}\right)$. We assumed Bayesian P-spline priors for the baseline and non-linear effects as in Lang and Brezger (2004). The P-splines allow for the non-parametric estimation of $f$ as a linear combination of basis function (B-splines), i.e. $p(z)=\sum_{j=1}^{J} \beta_{j} B_{j}(z)$ where $B_{j}(z)$ are B-splines and the coefficients $\beta_{j}$ are further defined to follow a first- or second-order random walk prior. In this case study, we assumed a second-order random walk, i.e. $\beta_{j}=2 \beta_{j-1}-\beta_{j-2}+\varepsilon_{t}$ with Gaussian error $\varepsilon_{t}^{\sim} N\left(0, \tau_{\varepsilon}^{2}\right)$. The variance $\tau_{\varepsilon}^{2}$ controls for the smoothness of $f$. For the fixed effects, we assigned diffuse priors.

To estimate the smoothing parameters $\sigma_{\phi}^{2}, \sigma_{\theta}^{2}$ and $\tau_{\varepsilon}^{2}$ simultaneously with all the unknown smooth functions, highly dispersed but proper hyperpriors are assigned to them. An inverse gamma distribution with hyperparameters $a$ and $b$ was chosen, e.g. $p\left(\tau_{\varepsilon}^{2}\right)^{\sim} I$ $G\left(a_{j}, b_{j}\right)$. Standard choices for the hyperparameters are $a=1$ and $b=0.005$ or $a=b=$ 0.001 . The latter choice is close to Jeffrey's non-informative prior. Sensitivity analysis was performed by using different values for the hyperparameters, but the results turned out to be less sensitive to the different choices. The results presented are those for $a=b=0.001$. 
Bayesian inference is based on the posterior distribution of model parameters, which is not of a known form. Therefore, MCMC sampling from full conditional for all the effects is used for posterior analysis. To implement the models, a total of 35,000 iterations were carried out, with the first 5000 discarded as burn-in and every 10th observation was thinned for parameter estimation. Convergence was also assessed through autocorrelation functions and trace plots. Model comparison was based on deviance information criterion (DIC) (Spiegelhalter et al. 2002), in which the model with the lowest DIC value is considered the best.

\section{Results}

The sequential analysis of the variables allows for a comprehensive understanding of the multifarious influences of the various categories of the variables across space. Four equations were examined. The first considers crude mortality across the geographical regions without adjusting for any variable. At subsequent steps, variables were added to the first equation. The second equation includes demographic variables intrinsic to the mother and child. In the third, mother's status variables were added to the second equation, while the amenity variables were added in the fourth model, making it the full model.

Table 3 presents results of the fixed parameters for equations two to four for children under the age of five. The results for the infants are similar with those for under-five children and hence are not presented. Presented are the posterior means and $95 \%$ credible intervals (CI). Also included in the table are the values of the DIC. Based on the DIC values, model fits improve as more variables were included; thus, the full model has the best fit. Results of the fixed effects largely conform to previous studies on child mortality in sub-Saharan Africa. Children in rural areas stand at higher risks of mortality compared with those dwelling in urban areas. Children of second and higher birth orders and those of single births were at lower risks of mortality compared with children of first and multiple births, respectively. Findings also show higher risks for male child, while those of sex of the household head were not significant.

Children whose parents attain secondary or higher education have lower risks of dying compared with those of parents without education. However, children whose parents possessed primary education had higher risks. Results for wealth indicator show that, compared with children from the poorest index households, those from the richest have lower risks of mortality, while results for the other categories are not significant. Working women have higher risks of child mortality compared with those not working. Children from households with electricity, improved toilet facilities, and who source their water from a pipe and those delivered at hospitals have lower risks of dying compared with their other counterparts. Results on mass media reflect that children whose mothers listen to radio at least once a week have higher risks of mortality while estimates for television and newspaper are not significant. Results for type of cooking fuel are equally not significant.

The estimated posterior means and $95 \%$ CI for child's age (baseline) and mother's age for children under five and infants are presented, respectively, in Figs. 2 and 3. Similar estimates were obtained for all the models; hence, only those of the full models are shown. The baseline for children under five shows a quick reduction in risks of mortality between age 0 and 1 followed by a more or less constant pattern till around 
Table 3 Posterior estimates for the fixed effects parameters for under-five mortality. Included are the values of the deviance information criteria (DIC)

\begin{tabular}{|c|c|c|c|c|c|c|}
\hline \multirow[b]{2}{*}{ Variables in model } & \multicolumn{2}{|l|}{ Model 2} & \multicolumn{2}{|l|}{ Model 3} & \multicolumn{2}{|l|}{ Model 4} \\
\hline & $\begin{array}{l}\text { Posterior } \\
\text { mean }\end{array}$ & $\begin{array}{l}\text { Credible } \\
\text { interval }\end{array}$ & $\begin{array}{l}\text { Posterior } \\
\text { mean }\end{array}$ & $\begin{array}{l}\text { Credible } \\
\text { interval }\end{array}$ & $\begin{array}{l}\text { Posterior } \\
\text { mean }\end{array}$ & $\begin{array}{l}\text { Credible } \\
\text { interval }\end{array}$ \\
\hline \multicolumn{7}{|l|}{ Individual characteristics } \\
\hline \multicolumn{7}{|l|}{ Place of residence } \\
\hline Urban & 0 & & 0 & & 0 & \\
\hline Rural & 0.212 & $0.181,0.245$ & 0.093 & $0.053,0.135$ & 0.053 & $0.010,0.092$ \\
\hline \multicolumn{7}{|l|}{ Birth order } \\
\hline 1st birth & 0 & & 0 & & 0 & \\
\hline 2nd or 3rd order & -0.099 & $-0.140,-0.056$ & -0.102 & $-0.143,-0.063$ & -0.104 & $-0.146,0.057$ \\
\hline 4th or higher order & -0.358 & $-0.410,-0.307$ & -0.444 & $-0.499,-0.392$ & -0.468 & $-0.523,-0.062$ \\
\hline \multicolumn{7}{|l|}{ Multiple birth } \\
\hline Yes & 0 & & 0 & & 0 & \\
\hline No & -0.545 & $-0.597,-0.496$ & -0.551 & $-0.603,-0.502$ & -0.568 & $-0.617,-0.518$ \\
\hline \multicolumn{7}{|l|}{ Sex } \\
\hline Female & 0 & & 0 & & 0 & \\
\hline Male & 0.067 & $0.043,0.096$ & 0.070 & $0.044,0.096$ & 0.072 & $0.046,0.097$ \\
\hline \multicolumn{7}{|c|}{ Sex of the household head } \\
\hline Male & 0 & & 0 & & 0 & \\
\hline Female & 0.007 & $-0.032,0.049$ & -0.013 & $-0.028,0.052$ & 0.015 & $-0.026,0.057$ \\
\hline \multicolumn{7}{|l|}{ Status variables } \\
\hline \multicolumn{7}{|l|}{ Educational attainment } \\
\hline No education & & & 0 & & 0 & \\
\hline Primary & & & 0.083 & $0.030,0.096$ & 0.083 & $0.030,0.136$ \\
\hline Secondary or higher & & & -0.280 & $-0.341,-0.219$ & -0.253 & $-0.323,-0.183$ \\
\hline \multicolumn{7}{|l|}{ Wealth } \\
\hline Poorest & & & 0 & & 0 & \\
\hline Poorer & & & 0.163 & $0.0110,0.217$ & 0.088 & $-0.029,0.049$ \\
\hline Middle & & & 0.046 & $-0.008,0.101$ & 0.015 & $-0.040,0.072$ \\
\hline Richer & & & -0.018 & $-0.073,0.037$ & 0.022 & $-0.037,0.080$ \\
\hline Richest & & & -0.278 & $-0.366,-0.193$ & -0.092 & $-0.198,0.008$ \\
\hline \multicolumn{7}{|l|}{ Working status } \\
\hline No & & & 0 & & 0 & \\
\hline Yes & & & 0.151 & $0.120,0.181$ & 0.153 & $0.121,0.183$ \\
\hline \multicolumn{7}{|l|}{ Amenity variables } \\
\hline \multicolumn{7}{|l|}{ Has electricity } \\
\hline No & & & & & 0 & \\
\hline Yes & & & & & -0.054 & $-0.099,-0.010$ \\
\hline \multicolumn{7}{|l|}{ Toilet facility } \\
\hline Non-improved & & & & & 0 & \\
\hline Improved & & & & & -0.053 & $-0.089,-0.018$ \\
\hline \multicolumn{7}{|l|}{ Water source } \\
\hline Others & & & & & 0 & \\
\hline Surface & & & & & 0.014 & $-0.065,0.096$ \\
\hline Well & & & & & 0.019 & $-0.048,0.085$ \\
\hline
\end{tabular}


Table 3 Posterior estimates for the fixed effects parameters for under-five mortality. Included are the values of the deviance information criteria (DIC) (Continued)

\begin{tabular}{|c|c|c|c|}
\hline Pipe & & -0.076 & $-0.157,0.006$ \\
\hline \multicolumn{4}{|l|}{ Place of delivery } \\
\hline Any other place & & 0 & \\
\hline Hospital & & -0.177 & $-0.209,-0.146$ \\
\hline \multicolumn{4}{|c|}{ Exposure to mass media } \\
\hline Newspaper & & 0.012 & $-0.052,0.079$ \\
\hline Radio & & 0.033 & $0.004,0.063$ \\
\hline Television & & -0.036 & $-0.074,0.001$ \\
\hline \multicolumn{4}{|c|}{ Type of cooking fuel } \\
\hline Any other & & 0 & \\
\hline Electricity/gas & & -0.126 & $-0.341,0.088$ \\
\hline Kerosene & & -0.033 & $-0.187,0.116$ \\
\hline Wood & & 0.037 & $-0.065,0.141$ \\
\hline DIC & 39944.611 & 39532.862 & \\
\hline
\end{tabular}

age 12 months where a small bump is observed, which could be due to heaping. Thereafter, there is a gentle fall till around age 16 months before the curve rises gently again between ages 21 and 24 months. Next is a sinusoidal pattern before a drastic fall from around age 50 months. The baseline for the infant data equally shows that there is a sharp drop in risks of mortality at the neonate age. The estimated non-linear effect of mother's age shows that the risks of mortality for children under 5 years of age rise steadily till around age 49 years, but not without a little bend around ages $23-25$ years. The estimated effects for the infants show a somewhat opposite pattern when put sideby-side with the curve for children under five. It shows a uniform level for ages 15 to 30 years before rising steadily.

Results from the spatial analyses are presented in Figs. $4 \mathrm{a}-\mathrm{h}$ and $5 \mathrm{a}-\mathrm{d}$ for children under five and the infants, respectively. The left panels show the posterior means, while the right panels display the maps of $95 \%$ CI. The CI maps are used to determine the significance of the estimates. Maps shaded white (black) signify significantly higher (lower) risks, while estimates for locations in grey colour are not significant. Spatial effects for the crude analysis (Fig. 4a, b) show that the risks are significantly lower for children from the Southern (except South East) and North Central regions of Nigeria; Agadez and Diffa regions of Niger; Borgou, Plateau, Oueme, Cotonou and Atlantique regions of Benin; Western and Volta regions of Ghana; neighbouring Sud-Ouest and Centre-Ouest regions of Ivory Coast; North Central region of Liberia; and Koulikoro, Mali. On the other hand, risks are significantly higher in the North East and North West regions of Nigeria; Tillabéri and Dosso regions of Niger; Cascades, Sahel, Sud-Ouest, Nord and Est regions of Burkina Faso; the whole of Sierra Leone; neighbouring Faranah and Kankan regions of Guinea; Ségou of Mali; Nord and Nord-Ouest regions of Ivory Coast; and North Western and South Eastern B regions of Liberia.

Inclusion of demographic variables and controlling for the unstructured spatial effects via a random effect component, a proxy for unmeasured risks factors, drastically changed the observed crude spatial pattern. The results show significantly higher risks in all the regions of Sierra Leone; Faranah and Kankan regions of Guinea, which are 

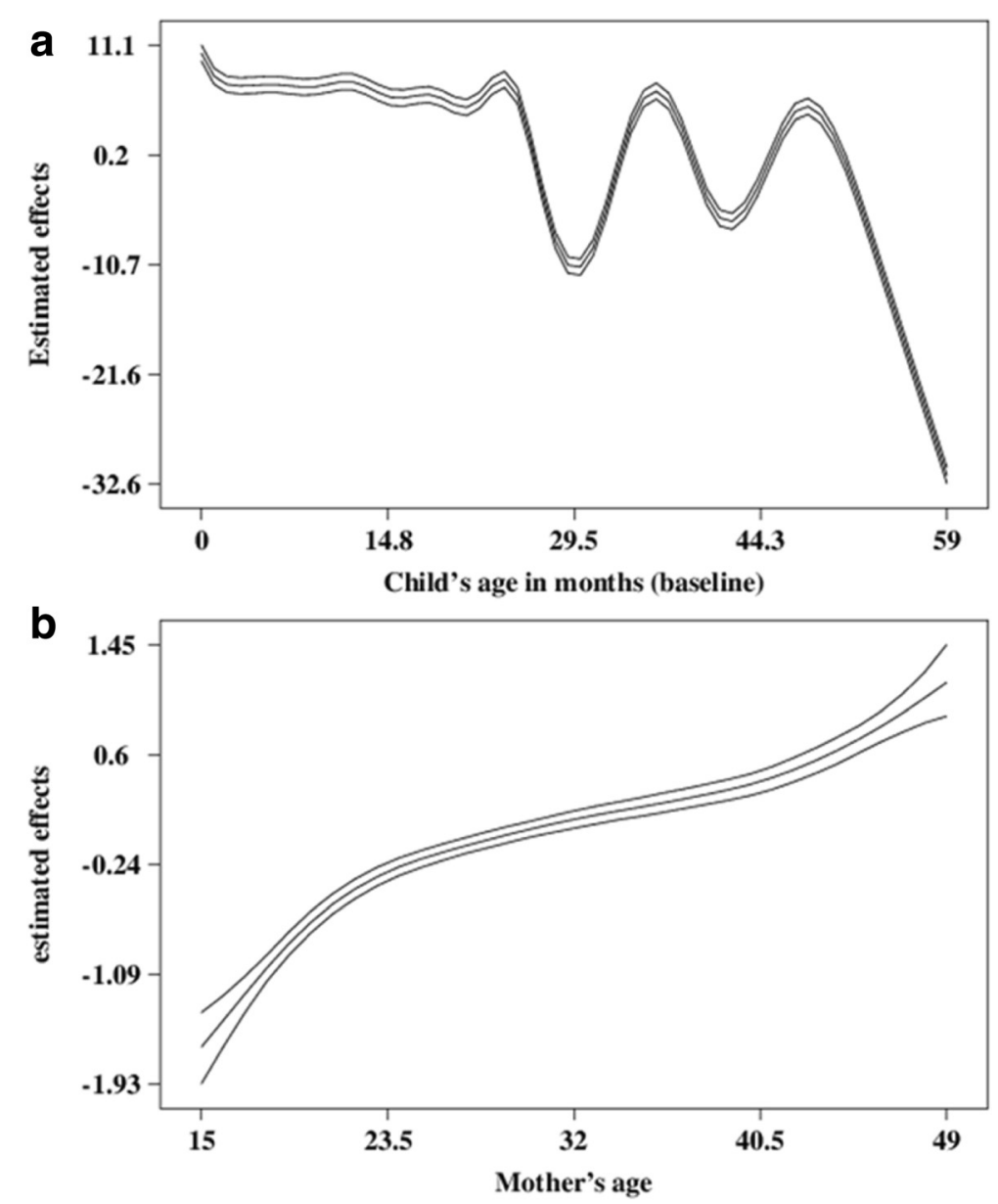

Fig. 2 Estimated effects of baseline time (a) and mother's age (b) for children under 5 years of age. Shown are the posterior means and $95 \% \mathrm{Cl}$

neighbours to Sierra Leone; and Cascades and Sahel regions of Burkina Faso. Significantly lower risks are obtained for the South West region of Nigeria; Plateau, Oueme, Cotonou and Atlantique regions of Benin; and Volta region, Ghana. Adding mother's status variables only changed the spatial pattern obtained from the second model slightly. For instance, the results show high risks in the neighbouring North West (Nigeria), Dosso, Tillabéri (Niger) and Sahel (Burkina Faso), while the risks are no more significant in South West Nigeria. Results of the full equation reveal that when demographic, status and amenity variables are accounted for, the risks of mortality among children under five are only significantly higher in the Southern region of Sierra Leone but lower in Plateau, Benin, but not significant for all other regions.

Results obtained from analysing the infants' data are somewhat different from those of under-five children. Significant risks are observed only in the results of the first equation. As the demographic variables were included, the risks are not significant for any region. Therefore, we present only the outcomes of the first and last equations in Fig. 5a-d. Findings from the first equation show that of the 10 countries analysed, the risks of infant mortality are merely significantly higher in three regions: the Southern and Eastern regions of Sierra Leone and North Western region of Liberia. The map of 

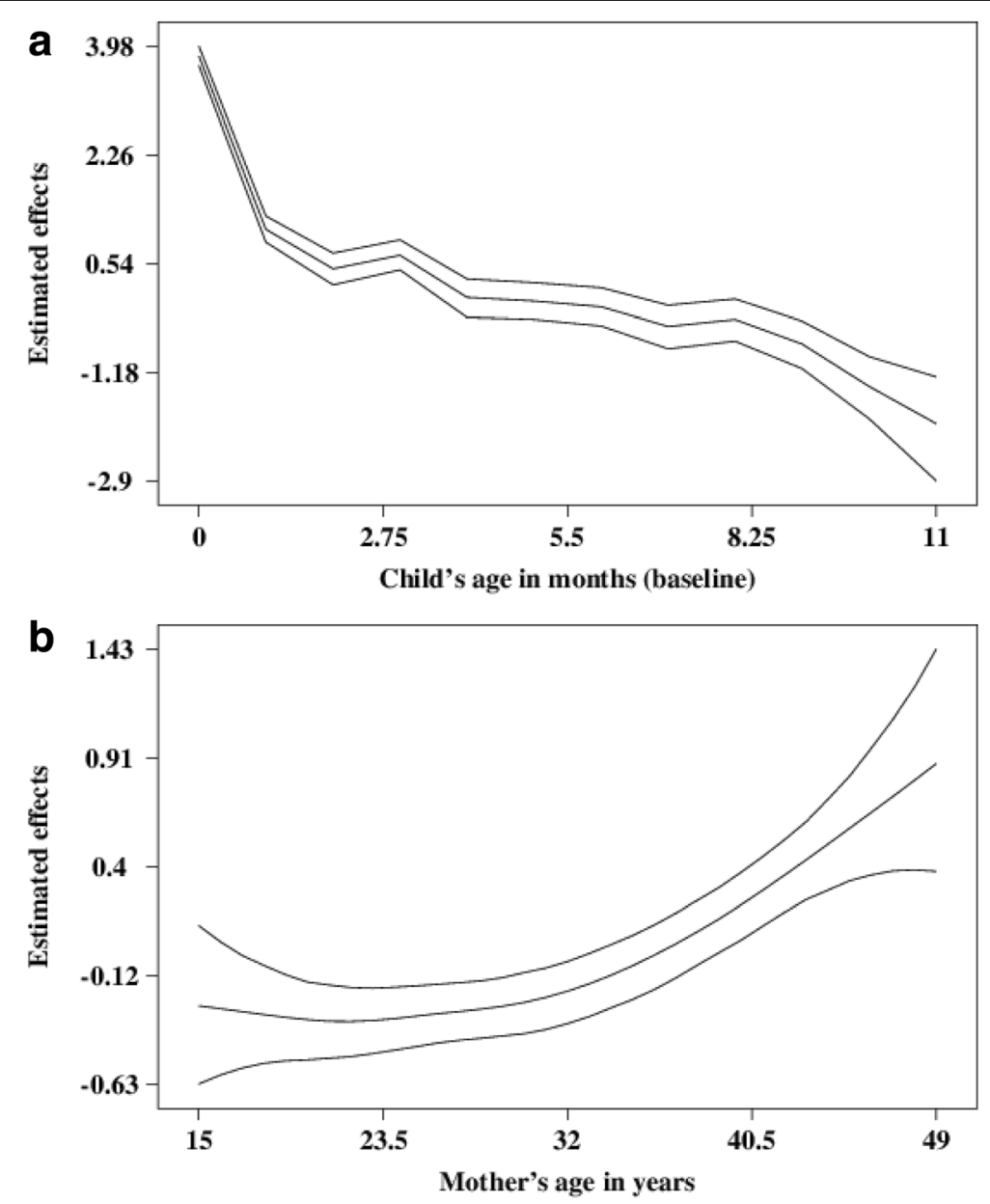

Fig. 3 Estimated effects of baseline time (a) and mother's age (b) for infants. Shown are the posterior means and $95 \% \mathrm{Cl}$

the posterior means shows that some parts of Niger, Mali and Burkina Faso are places where risks of infant mortality are lower, albeit these are not significant.

\section{Discussions of results}

This study aimed at disentangling the spatial variations of child mortality in West African countries in a manner that transcends regional boundaries and therefore offers some insights into the disparity in the experience in a region that contributes largely to children deaths in sub-Saharan Africa. The method and strategy of analysis employed made it possible to discern regional specific effects and how different categories of variables exert influence leading to variations in chances of child survival across space. Though the differences in mortality in West African nations might have been shown using traditional parametric approaches, the Bayesian geo-additive method employed is able to uniquely discern subtle region-specific differences. Adopting methods that create dummies for the regions would unnecessarily upsurge the number of parameters to be estimated and could lead to unstable estimates.

A major finding from this study is that patterns of under-five mortality in West Africa have spatial structure that surpass geographical boundary where similar patterns 


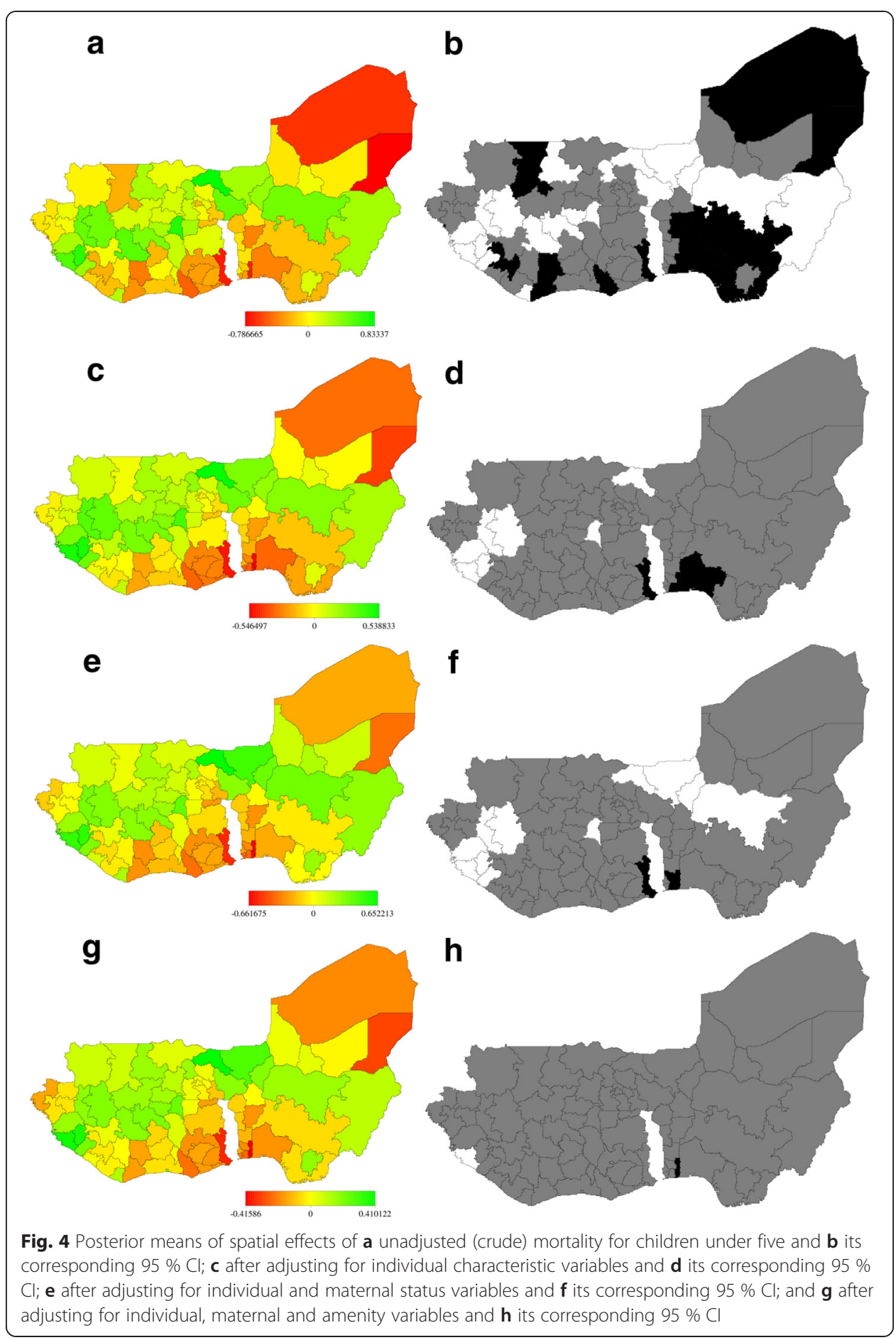

were observed for neighbouring countries. This is however not the situation in the case of infants where the structure is uniform to some extent. For instances, in respect to other regions, under-five deaths are significantly higher in northwest and northeast Nigeria, a pattern that transcends to neighbouring southwest of Niger. This spatial clustering in the part of Sahel persists even after controlling for some variables. Another clustering was obtained in Sierra Leone, parts of Guinea and neighbouring western regions of Liberia. On the other hand, significantly lower levels were obtained 


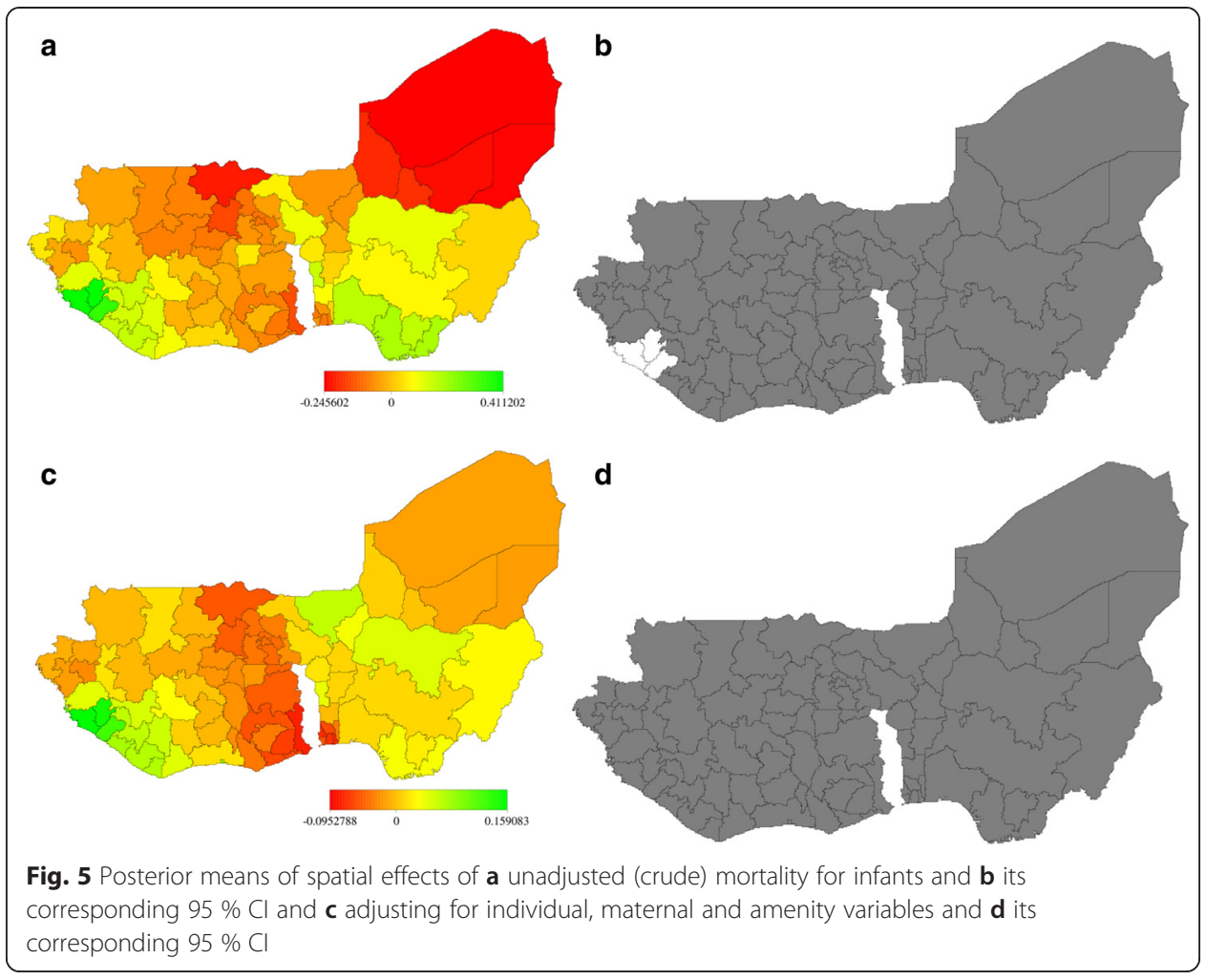

in the southern Nigerian and neighbouring regions of Benin. The findings may partly be explained by similar prevalence of shared childhood diseases, general healthcare practices and residual spatial variation swayed by variation in unexplained region-specific traits. The Sahel region is typically dry, hot, sunny and somewhat windy all year long and is associated with some diseases, such as cerebrospinal meningitis characterized by high fever, skin rash stupor and sometimes coma, which affect humans particularly children which could account for the clustering in the portion of the region. The Sahel region has also continued to face food insecurity leading to severe acute malnutrition among children (European Commission 2014; West Africa Regional Health Working Group 2012). The fact that infants depend much on breast milk from their mothers makes them less vulnerable to strong food reduction, except if breastfeeding is not exclusive or malnutrition severely affects the mother. Thus, the spatial structure does not show evidence of strong variation among infants, even when the crude data was fitted.

It is noteworthy that the strong spatial structure of Sierra Leone and neighbouring Guinea could only be disentangled by accounting for amenity variables. This underscores the importance of and state of social amenities in these countries. Already, pervasive poverty, high level of illiteracy among women, limited access to safe drinking water and adequate sanitation, poor feeding and hygienic practices, overcrowded housing and limited access to quality health services have been adduced as the causes of huge childhood morbidity and mortality in these regions (Tomori 2014; WHO 2009). Interventions that could lead to behavioural change in addition to improving the available social amenities in these two countries in particular and other West African countries would go a long way to ameliorate the survival chance of the young children. 
After controlling for spatial dependence in the data, the majority of the covariates in the fixed part of the models were found to have significant effects in the right direction. Findings on birth order, multiple births and gender for instance conform with existing literature on sub-Saharan Africa (Magadi et al. 2007; Manda 1999; Uthman et al. 2008). Multi-foetal pregnancy and multiple births including twins and higher order multiples such as triplets and quadruplets are known to be high-risk pregnancies and births while first births are likely to have occurred to inexperienced mothers. Biological hardiness and gender preference especially resulting from perceived bride price to be earned could account for differences in mortality between genders (Fuse 2010).

Mother's educational status and household wealth index are important factors in explaining variations in infant and child mortality. The strong link between mother's education and child survival has led to the advocacy that enhancing mother's education be adopted as a strategy for reducing infant and child morbidity and mortality (Adebayo et al. 2013; Folasade 2000; Gayawan 2014b; Hobcraft 1993). Our findings show higher chances of child mortality for children whose parents attained primary education against those whose parents had no education. This therefore reaffirms the need to raise maternal education to at least the secondary level in West African countries. Children born to poor households are faced with challenges such as insufficient food intake and lack of access to basic healthcare. The results of the household wealth index are rather fascinating. We found significantly lower risks for children from the richest quantum in the model without amenity variables, but this was no more statistically significant when these variables where included. The implication is that, with the prevailing level of social amenities in West Africa, the impact of family wealth on child mortality becomes weak. Similar to results from Nigeria (Adebayo and Fahrmeir 2005), Malawi (Manda 1999) and Bolivia (Forste 1994), working women had higher child mortality than the non-working. One would have expected the opposite. However, majority of the people who live in the major cities of sub-Saharan countries, where gainful employment could be found, live in sprawling settlements that are often overcrowding with poor sanitation (Manda 1999; Mutunga 2004).

The import of household electricity, improved toilet facilities and delivery at hospital facilities to child survival as indicated by this study cannot be overemphasized. Electricity in households provides energy needed in boiling and preservation which prevents diarrhoeal diseases and respiratory infections in cold climate, but many households in West Africa are still without the essential commodity. The use of pit latrine and other surfaces for passing excreta has been shown to be higher risk morbidity and mortality among children because they are easy source of contamination (Folasade 2000). The non-significance of water source might result from the fact that in most West African countries, pipes are often dry, leaving the people to source their water from other available sources. On the place of delivery, some African countries including Equatorial Guinea, Morocco, Rwanda, Egypt, Angola and Niger have adopted the strategy of increasing the proportion of births attended to by skilled attendants as a way of reducing incidences of maternal and child mortality and this is yielding positive results (MDG Report 2012).

Results of mother's age for both infants and children under five display similar patterns to what were obtained in separate analyses of Nigerian data by Adebayo and Fahrmeir (2005) and Ghilagaber et al. (2014). The patterns emphasized that 
risks are associated with late childbirth, while, as previously stated, children born to much older women compete for limited resources, and these women also rely on previous experiences and therefore refuse to seek for expert help during childbirth (Babalola and Fatusi 2009; Onah et al. 2006; Wagle et al. 2004). Such experiences might also be relied upon in dealing with childhood diseases. The baseline effects demonstrate that risks of dying are highest in the first month of life and reduce thereafter. Cost-effective interventions, such as early post-natal home visits and case management of neonate infections, need to be intensified in all West African countries.

\section{Conclusion}

The influences of different categories of demographic and socioeconomic variables on the spatial structure of infants and child mortality have been scrutinized. The modelling approach was apparently able to discern imperceptible influences and identify regionspecific clustering. The results demonstrate that, in West African countries, under-five mortality is spatially structured with adjusted mortality risks displaying similar patterns among neighbouring regions/countries which might be attributed to common childhood disease prevalence, general healthcare practices, similar poverty level and acute malnutrition caused by food insecurity. However, in the case of infant mortality, the results do not present evidence of pronounced spatial variations. Cost-effective interventions would be required to save the lives of these children. Findings from this study, particularly from the maps generated, could help policymakers and international donors in their various intervention programmes aimed at saving the lives of young children.

Competing interests

The authors declare that they have no competing interests.

\section{Authors' contributions}

EG conceived the idea, participated in data collation, data analysis and drafting of manuscript. MIA involved in method development and drafting of manuscript. DMO participated in data collation and drafting of manuscript. SGF participated in data analysis and drafting of manuscript. JCU was involved in drafting of manuscript. All authors read and approved the final manuscript.

Acknowledgements

The authors thank The DHS Program for granting them access to the data analysed in the study.

\section{Author details}

${ }^{1}$ Department of Statistics, Federal University of Technology, Akure, PMB 704 Akure, Ondo State, Nigeria. ${ }^{2}$ Department of Mathematical Sciences, Redeemer's University, Ede, Nigeria. ${ }^{3}$ Department of Mathematics and Physical Sciences, Afe Babalola University, Ado Ekiti, Nigeria. ${ }^{4}$ Department of Computer Science, Kampala International University, Kampala, Uganda.

Received: 17 November 2015 Accepted: 15 March 2016

Published online: 14 July 2016

\section{References}

Adebayo, S. B., \& Fahrmeir, L. (2005). Analysing child mortality in Nigeria with geoadditive discrete-time survival models. Statistics in Medicine, 24(5), 709-728.

Adebayo, S. B., Fahrmeir, L., \& Klasen, S. (2004). Analyzing infant mortality with geoadditive categorical regression models: a case study for Nigeria. Economics and Human Biology, 2, 229-244.

Adebayo, S. B., Gayawan, E., Ujuju, C., \& Ankomah, A. (2013). Modelling geographical variations and determinants of use of modern family planning methods among women of reproductive age in Nigeria. Journal of Biosocial Science, 45(1), 57-77. doi:10.1017/S0021932012000326.

Adetunji, J. A. (1995). Infant mortality and mother's education in Ondo State, Nigeria. Social Science and Medicine, 40(2), $253-261$.

Atari, D. O., \& Mkandawire, P. (2014). Spatial variation of management of childhood diarrhea in Malawi. Health \& Place, $29,84-94$.

Babalola, S., \& Fatusi, A. (2009). Determinants of use of maternal health services in Nigeria-looking beyond individual and household factors. BMC Pregnancy Childbirth, 9, 43(43). doi:10.1186/1471-2393-9-43. 
Balk, D., Pullum, T., Storeygard, A., Greenwell, F., \& Neuman, M. (2004). A spatial analysis of childhood mortality in West Africa. Population, Space and Place, 10, 175-216.

Besag, J., York, Y., \& Mollie, A. (1991). Bayesian image restoration with two applications in spatial statistics (with discussion). Annals of the Institute of Statistical Mathematics, 43(1), 1-59.

Caldwell, J. C. (1979). Education as a factor in mortality decline: an examination of Nigerian data. Population Studies, 33(3), 395-413.

Cleland, J. G., \& van Ginneken, J. K. (1988). Maternal education and child survival in developing countries: the search for pathways of influence. Social Science and Medicine, 27(12), 1357-1368.

Davies-Adetugbo, A. A. (1997). Sociocultural factors and the promotion of exclusive breastfeeding in rural Yoruba communities of Osun State. Social Science and Medicine, 45, 113-125.

Defo, B. K. (1996). Areal and socioeconomic differentials in infant and child mortality in Cameroon. Social Science and Medicine, 42(3), 399-420.

European Commission. (2014). Sahel: Food and Nutrition Crisis Humanitarian Aid and Civil Protection. Retrieved 13 October, 2014, from http://ec.europa.eu/echo/files/aid/countries/factsheets/sahel_en.pdf

Fahrmeir, L., \& Tutz, G. (2001). Multivariate statistical modelling based on generalized linear models (3rd ed.). New York: Springer.

Foggin, P., Armijo-Hussein, N., Marigaux, C., \& Zhu, H. (2001). Risk factors and child mortality among the Miao in Yunnan, Southwest China. Social Science and Medicine, 53, 1683-1696.

Folasade, B. I. (2000). Environmental factors, situation of women and child mortality in southwestern Nigeria. Social Science and Medicine, 51, 1473-1489.

Forste, R. (1994). The effects of breastfeeding and child mortality in Bolivia. Population Studies, 48, 397-511.

Fuse, K. (2010). Variations in attitudinal gender preferences for children across 50 less-developed countries. Demographic Research, 23(36), 1031-1048.

Gayawan, E. (2014a). A Poisson regression model to examine spatial patterns in antenatal care utilisation in Nigeria. Population, Space and Place, 20, 485-479. doi:10.1002/psp.1775.

Gayawan, E. (2014b). Spatial analysis of choice of place of delivery in Nigeria. Sexual \& Reproductive Healthcare, 5, 59-67.

Gayawan, E., \& Turra, C. M. (2015). Mapping the determinants of child mortality in Nigeria: estimates from mortality index. African Geographical Review, 34(3), 269-293. doi:10.1080/19376812.2015.1039553.

Gayawan, E., Arogundade, E. D., \& Adebayo, S. B. (2014). A Bayesian multinomial modeling of spatial pattern of comorbidity of malaria and non-malarial febrile illness among young children in Nigeria. Transactions of the Royal Society of Tropical Medicine and Hygiene, 108(7), 415-424.

Gesler, W. M. (1992). Cultural aspects in health care delivery. In R. Akhtar (Ed.), Environmental and health: Themes in medical geography (pp. 513-523). New Delhi: Ashish Publishing.

Ghilagaber, G., Diddy, A., \& Kandala, N. B. (2014). Modeling spatial effects on childhood mortality via geo-additive Bayesian discrete-time survival model: A case study from Nigeria. In N. B. Kandala \& G. Ghilagaber (Eds.), Advance techniques for modelling maternal and child health in Africa (Vol. 34, pp. 29-48). New York: Springer Dordrecht Heidelberg.

Hobcraft, J. N. (1993). Women's education, child welfare and child survival: a review of evidence. Health Transition Review, 3(3), 159-175.

Hossain, M., \& Islam, M. (2008). Effects of demographic and household variables on infant and child under-five mortality: an application of logistic model. The Internet Journal of Health, 8, 2.

Iyun, B. F. (1992). Women's status and childhood mortality in two contrasting areas in southwestern Nigeria: a preliminary analysis. GeoJournal, 26(1), 43-52.

Janjua, N. Z., Mahmood, B., Dharma, V. K., Sathiakumar, N., \& Khan, M. I. (2012). Use of biomass fuel and acute respiratory infections in rural Pakistan. Public Health, 126(10), 855-862.

Kalipeni, E. (1993). Determinants of infant mortality in Malawi: a spatial perspective. Social Science and Medicine, 37(2), 183-198.

Kandala, N. B., \& Gebrenegus, G. (2006). A geo-additive Bayesian discrete-time survival model and its application to spatial analysis of childhood mortality in Malawi. Quality \& Quantity, 40(6), 935-957. doi:10.1007/s11135005-3268-6.

Kandala, N. B., Magadi, M. A., \& Madise, N. J. (2006). An investigation of district spatial variations of childhood diarrhoea and fever morbidity in Malawi. Social Science and Medicine, 62, 1138-1152.

Kandala, N.-B., Ji, C., Stallard, N., Stranges, S., \& Cappuccio, F. P. (2007). Spatial analysis of risk factors for childhood morbidity in Nigeria. American Journal of Tropical Medicine and Hygiene, 77(4), 770-778.

Kazembe, L. N., \& Namangale, J. J. (2007). A Bayesian multinomial model to analyse spatial patterns of childhood comorbidity in Malawi. European Journal of Epidemiology, 22, 545-556.

Kembo, J., \& Van Ginneken, J. K. (2009). Determinants of infant and child mortality in Zimbabwe: results of multivariate hazard analysis. Demographic Research, 21(13), 367-384.

Klasen, S. (1996). Nutrition, health and mortality in Sub-Saharan Africa: is there a gender bias? Journal of Developmental Studies, 32, 913-932.

Lang, S., \& Brezger, A. (2004). Bayesian P-splines. Journal of Computational and Graphical Statistics, 13(1), 183-212.

Macassa, G., Ghilagaber, G., Benrhardt, E., \& Burston, B. (2004). Determinants of infant and child mortality in Zimbabwe: results of multivariate hazard analysis. East African Medical Journal, 81(8), 408-414.

Magadi, M. A., Agwanda, O. A., \& Obare, F. O. (2007). A comparative analysis of the use of maternal health services between teenagers and older mothers in sub-Saharan Africa: evidence from Demographic and Health Surveys (DHS). Social Science and Medicine, 64, 1311-1325.

Manda, S. (1999). Birth intervals, breastfeeding and determinants of childhood mortality in Malawi. Social Science and Medicine, 48(3), 301-312.

MDG Report. (2012). Assessing progress in Africa towards the millennium development goals. Adis Ababa: African Union Commission, United Nations Economic Commission for Africa, African Development Bank and United Nations Development Programme.

Miller, J. E., Trussell, J., Pebley, A. R., \& Vanghan, B. (1992). Birth spacing and child mortality in Bangladesh and the Philippines. Demography, 29, 305-318. 
Mturi, A. J., \& Curtis, S. L. (1995). The determinants of infant and child mortality in Tanzania. Health Policy and Planning, 10(4), 384-394.

Mutunga, J. C. (2004). Environmental determinants of child mortality in urban Kenya. Paper presented at the Discussion in an informal workshop held at Abdus Salam ICTP, Trieste, Italy

Onah, H. E., Ikeako, L. C., \& lloabachie, G. C. (2006). Factors associated with the use of maternity services in Enugu, southeastern Nigeria. Social Science and Medicine, 63, 1870-1878.

Osayande, C. (1998). Studies on exclusive breastfeeding: a report on associated factors in an African population. Journal of Tropical Pediatrics, 44, 172-173.

Pebley, A. R., \& Stupp, P. W. (1987). Reproductive patterns and child mortality in Guatemala. Demography, 24, 43-60.

Sastry, N. (1997). What explains rural-urban differentials in child mortality in Brazil? Social Science and Medicine, 44, 989-1002

Spiegelhalter, D. J., Best, N. G., Carlin, B. P., \& Van der Linde, A. (2002). Bayesian measures of model complexity and fit (with discussion). Journal of the Royal Statistical Society B, 64(4), 583-640.

Tomori, O. (2014). Ebola in an unprepared Africa. BMJ, 349, g5597. doi:10.1136/bmj.g5597.

UN Inter-Agency Group for Child Mortality Estimation. (2014). Levels and trends in child mortality. New York: UNICEF, World Health Organization, The World Bank, and United Nations.

Uthman, A. O., Uthman, M. B., \& Yahaya, I. (2008). A population-based study of effect of multiple birth on infant mortality in Nigeria. BMC Pregnancy Childbirth, 8, 41.

Wagle, R. R., Sabroe, S., \& Nielsen, B. B. (2004). Socioeconomic and physical distance to the maternity hospital as predictors for place of delivery: an observation study from Nepal. BMC Pregnancy Childbirth, 4, 8.

West Africa Regional Health Working Group. (2012). Sahel food and health crisis: emergency health strategy. Retrieved 13 October, 2014, from http://www.who.int/hac/sahel_health_strategy_21june2012rev.pdf

WHO. (2009). WHO country cooperation strategy 2008-2013. Sierra Leone: WHO regional Office for Africa.

Yassin, K. M. (2000). Indices and sociodemographic determinants of childhood mortality in rural Upper Egypt. Social Science and Medicine, 51(2), 185-197.

\section{Submit your manuscript to a SpringerOpen ${ }^{\circ}$ journal and benefit from:}

- Convenient online submission

- Rigorous peer review

- Immediate publication on acceptance

- Open access: articles freely available online

- High visibility within the field

- Retaining the copyright to your article

Submit your next manuscript at $\boldsymbol{\nabla}$ springeropen.com 